\title{
The RAF Community Psychiatry Service In Cyprus
}

\author{
FS R A Jones, \\ RMN, SRN \\ Community Psychiatric Nurse
}

Princess Alexandra's Royal Air Force Hospital, Swindon, Wilts, SN4 OQJ

\section{Introduction}

Royal Air Force (RAF) Community Psychiatric Services developed in the early $70 \mathrm{~s}$, and are now well established in the UK and Germany. The latest development has been to provide a service for military units in Cyprus, and this has been available since September 1988.

The Community Psychiatric Services in the UK and Germany operate from RAF Hospitals and provide a facility to surrounding military units. The structure of such a service is typically two Consultant Psychiatrists, three Community Psychiatric Nurses (CPNs), a Psychiatric Social Worker, and a visiting Clinical Psychologist. Inpatient facilities are available at RAF Hospitals.

The Community Psychiatry Service in Cyprus differs from its hospital based counterparts, consisting solely of one CPN who operates from the Station Medical Centre at an operational flying unit (RAF Akrotiri) supported by a Consultant Psychiatrist who visits the island for one week every two months.

This article reviews the aims of Community Psychiatry in a military setting, examines the methods used to achieve those aims in Cyprus, discusses specific difficulties and suggests changes.

\footnotetext{
Aims of Community Psychiatry

The aim of Community Psychiatry is to promote psychological well-being in a military environment, detect psychological disorders early in their course, and provide adequate psychiatric care to those who require it. The benefits that accrue from a functioning service are numerous. Preventative measures, liaison with work supervisors, early unit-based treatments, and appropriate environmental manipulations, all reduce the severity and duration of most common psychological problems. Furthermore, there are benefits for the military organisation. Fewer skilled tradesmen are discharged from the RAF, speedier occupational adjustment and rehabilitation is promoted, there is less unnecessary expenditure on hospital visits and admissions, and the requirement to repatriate Servicemen to the UK for treatment is greatly reduced.

The value of the CPN in offering practical advice to supervisors regarding an individual's fitness to carry out certain aspects of military service cannot be underestimated. There is often considerable anxiety concerning a person's suitability to perform weapon handling duties, work with complex and dangerous equipment, and handle sensitive Service information.
}

\section{Achieving the Aims}

The CPN is responsible for the following:-

1. Providing the CPN service for RAF and Army unitso in Cyprus visiting each major unit weekly. Referrals are initiated by a wide range of agencies: unit medical $\overrightarrow{0}$ officers, social workers and health visitors, volunteer $\overrightarrow{\vec{\omega}}$ services, the RELATE consellor, padres and mem- $\stackrel{\omega}{-}$ bers of the executive. Referrals require the patient's agreement, and appointments are arranged within $143^{\circ}$ days of receipt.

2. Interviewing and treating patients at locations con- $\vec{\omega}$ venient to them, such as at work, at home, or in the medical centre. A degree of sensitivity in this area can help reduce the stigma of referral and therefore helpor the patient to be more willing to receive necessagy psychiatric care.

3. Liaison with the visiting Consultant Psychiatrist, who conducts clinics at each of the main military uni $\vec{B}, \widehat{D}$ and advises member of the Primary Health Came Team, Personnel and Welfare staff, and the Statigne executive is required. The psychiatrist also provide continuing education in recent psychiatric trenc. These bi-monthly visits are supplemented by reguf telephone contact during the psychiatrist's period $\overrightarrow{\mathrm{of}}$ absence.

4. Liaison with primary care medical staff. For the majority of the time the CPN is without directō psychiatric supervision, but for administrative purposes he is directly responsible to the Senior Medical Officer at RAF Akrotiri, although he is responsible to all Unit Medical Officers for patient care. Being based within the Medical Centre at RAF Akrotiri greatly enhances the communication with the Primary Care Team as they are seen on a daily basis.

5. Liasion with the hospital specialist Soldiers, Sailors, Air Force Association (SSAFA) social workers, padres, work supervisors and station executives, ando volunteer groups. Such liaison is formalised by way of monthly Primary Health Care Team meetings, 0 attendance at Welfare Steering Group meetings, and monthly seminars organised by the Personnel Man-o agement Section. Naturally, most liaison occurs outside such structured occasions. Although there is aô potential conflict between the need for the militaryn organisation to know of individuals who may pose aN risk within the working environment, and the need to 
maintain the secrecy of information given in confidence, much can be shared amongst interested parties with the patient's consent. This can greatly reduce uncertainty and unnecessary anxieties and promote advantageous environmental changes for the patient. Voluntary organisations have proved invaluable in working with patients as co-therapists, under CPN supervision, thus relieving much of the workload.

6. Providing specific psychiatric therapies, such as individual and group therapy, marital and family counselling, cognitive and behavioural therapies, and treatment for alcohol related problems. This range of therapies requires experience and confidence particularly in view of the lack of supervision and the professional isolation.

7. Educational duties, including seminars for medical and nursing staff and voluntary agencies, and generally promoting awareness of the prevalence of psychological problems and the facilities available for their treatment.

8. All routine administration, such as booking clinics, arranging visits, collating monthly statistics, raising documentation and other miscellaneous clerical tasks.

\section{Problems Specific to Cyprus}

Although the prospect of a tour of duty on a historic, sun-drenched Mediterranean island seems very desirable, for many Servicemen and their families the reality can be much less appealing. There is frequently a period of difficult adjustment as the impact of decreased social support facilities, poor communication systems, unreliable public transport and telephone networks takes effect. Despite the availability of stand-by flights back, the UK contact with other family members is much diminished, heightening the initial sense of loss.

Most families are accommodated in quarters on military units, but unavoidably some are housed in local towns where they find themselves in a strange new community, surrounded by people whose language they do not share. For some wives the sense of isolation and alienation can be overwhelming. High pressure car salesmen may entice families into debts they can ill afford, and the very low price of alcohol can lead to an increase in consumption, all adding to the total burden of difficulties. Naturally too, there is a high demand for families to entertain relatives and friends from the UK $\stackrel{5}{\rightarrow}$ who seize the opportunity for a cheap sunshine holiday, $\bar{Z}$ which can prove wearing after the first few occasions.

\section{Discussion and Suggestion}

There is no doubt that living on, and working from, an operational RAF base greatly enhances the development of understanding and rapport between the Psychiatric Service and Station executive and work supervisors. This benefits the patient and their employer to a greater degree than is possible from a hospital based service. However, the workload for a single CPN looking after four major and two minor military units, including all their dependants, is too high, leaving little opportunity for further training, research or reading. This is particularly disadvantageous as the professional isolation further limits the opportunity for support, encouragement and professional refreshment.

There is also a feeling that, although the Communit Psychiatry Service has proved invaluable, it is spreag rather too thinly, leading to inefficient or frankly inad? equate delivery at busy times.

The situation cannot be changed at present because of a shortage of suitably qualified and experienced staf although an untapped resource for assistance is presef in the form of trained wives of Servicemen.

The medical screening of Servicemen and their dependants before posting to Cyprus, should include their psychiatric background. This precaution could further reduce some of the workload. 